\title{
A Philosophical Inquiry into the Future as a Category of Historical Time
}

\begin{abstract}
The significance of future as a category of historical time necessarily refers to the classical Koselleck's study about the origins of history as Geschichte. Indeed, history proper is only possible when the time is released from the divine power, then history appears as the result of the human actions. This idea reformulates a Kantian thesis about the plan of history. As it is known, according to Kant history has a meaning and a direction but this cannot put at risk the freedom of humans as moral agents. The future plays here a main role because it allows thinking about the progress of mankind as a regulative ideal. The concept of hope is its necessarily counterpart. In the realm of practical reason the hope works as the basis for our belief in a better world caused by our collaboration (when the good and the virtue go together). In history, this hope is expressed through the expectation of perpetual peace. It is obvious that the future cannot be an object of history because to talk about it would be to make prophecies (as Danto says). But it can be said that without future there is not history in its proper sense. Our aim here is to analyze the role of future as a component of historical consciousness and consequently to show its importance to understand why the human groups build their memories as a legacy for the next generations. In order to do this I intend to identify the political aspects of the hope displayed when the communities seek to conform and keep their collective memory as a heritage to leave for future generations.
\end{abstract}

\section{Introduction}

Every community relies on the future as a temporal dimension that organizes its present and, at the same time, gives meaning to its past. Human communities, whose expectations are often related to a better future for those to come, trans-

A longer version of this paper was presented in the 2nd INTH Network Conference: "The Practical Past: on the advantages and disadvantages of history for life" (Ouro Preto, August 2016). I am thankful to Timothy Ostrom for this English version.

Rosa E. Belvedresi, Universidad La Plata (Argentina) / Centro de Investigaciones Filosóficas (CIF)

Ә OpenAccess. (c) 2018 Rosa E. Belvedresi, published by De Gruyter. (cc) BY-NC-ND This work is licensed under the Creative Commons Attribution-NonCommercial-NoDerivatives 4.0 License. 
mit to 'the newcomers' a stock of accumulated knowledge that will prove useful in the further advancement of their lives (Arendt 1968). Within this social dynamic, the past and future function as indispensable temporal dimensions. New generations represent the future in the here and now, and they are the ones who ensure the continuing survival of the group in time. What they deem important and choose to transmit to other new generations constitutes a set of skills, meanings and worldviews, preserved from an earlier time (past) with the hope that it will be passed on to the future.

We shouldn't conclude from these statements that such communities are homogeneous; it is possible for that which they deem important to transmit to be composed of heterogeneous sets of the 'goods', which different groups value differently, which are not organized in a hierarchical manner and which are not consistent with each other. Nor should it be assumed that the transmission of what is considered significant happens 'democratically'. The goods to be transmitted are, in the end, symbolical and cultural resources, which, like any other resource, are unequally distributed. We will return to this issue below.

What I am concerned with analyzing here is the availability of the future as a dimension of historical consciousness, in relation to the ways in which social communities choose to conserve that which they wish to transmit to coming generations. I am referring to what I denominate, in general terms, 'inheritance'. By this, I understand that which is transmitted from generation to generation and constitutes the common backdrop that enables the group to conserve its identity and strengthen the sense of belonging of its members. I believe that, in this manner, it will be possible to recover the concept of hope in a political and historical sense, stripped of its religious connotations (insofar as it remits to the theological virtue).

It's clear that since the eighties we have been living in a world immersed in what is referred to as the 'memory boom'. This situation has been critically analyzed by such authors as A. Huyssen and F. Hartog, who think that the emphasis on memory in current Western societies doesn't shed sufficient light on the complex ways that symbolic constructions (which communities pass on as their inheritance) are constituted. Huyssen has established connections between the excess of memory and a certain risk of amnesia, whereas Hartog has identified the oppressive danger in the current attempt to turn everything into something worth remembering. Having said that, what interests me here is the possibility of understanding the current state of collective memory as a symptom of modes of conceptualizing the future, for which the aforementioned notion of 'inheritance' will prove useful. 


\section{Future and history}

The future is a temporal dimension that remits to that which could occur in a moment that hasn't yet transpired. It is a characteristic specific to the human consciousness of time; for Kant it is the anticipation of the future that distinguishes human beings from other species. This anticipation does not only include the more or less specific prediction of what is to come, but it is also molded by an important degree of uncertainty. (Later, we will return to this dual character of the future.)

The association of the future with history is nothing new. A. Danto (1985) had already pointed this out when he critiqued the prophetic aspect of speculative philosophies; in other words, he criticized them for concerning themselves with that which is outside of the scope of history, namely that which has yet to occur. Danto dealt the last blow to the aspirations of historical teleologies by formulating the following 'puzzle': "If I can do something about the future, the future cannot be known; and if it can be known, we can do nothing about it” (1985, p. 11). While it's true that he rejects the idea of formulating historical prophecies, on the other hand he gives the future a positive meaning within historical comprehension. Firstly, he exposes the uselessness of the 'Ideal Chronicler' who, lacking perspective on the future, is incapable, strictly speaking, of accounting for what happens. Thus, he reaches the following conclusion: "not being witness to the event is not so bad a thing if our interests are historical" (1985, pp. 152-3), since without this perspective on the future it is impossible to comprehend what it is that happened. Secondly and related to the first, not only do we not know the future, but we don't even know which history will be written of the moment that we are living, because the selection, description and interpretation of the events that are considered historical are dependent upon interests that we ignore. The historians of the future will have to be the ones who relate these events to others that haven't yet happened (1985, p. 169).

In this way, Danto considers that the thesis that history is constantly being re-written is justifiable, which enables us to assert that historicism, in a certain sense, is trivially true. His analysis also enables us to account for something that is often underestimated in the study of collective memory, such as the fact that the distinction between events that are 'worthy of remembering' and those considered unworthy doesn't have to do with any fixed aspect or inherent condition, but rather with the ways in which they are deemed meaningful by those who evaluate them.

So far, we can identify a double valuation of the future. As a perspective on predictions concerning the actions we are currently involved in, it is necessary to 
depend on the future in order to make descriptions that correspond to what we are doing in the present. Without a minimum prediction of what would occur as the result of our present actions, it wouldn't be possible to account for the set of movements of which they are comprised. But, secondly, the future is also open and unpredictable, and any attempt to delimit it or to speak about it causes us to run the risk of reverting to prophecy.

Koselleck, for his part, identifies different ways in which the future can be accounted for in the comprehension of history. It no longer has only to do with the distance between expectation and experience-as in his celebrated thesis about modernity-but rather with the degree to which we can speak reasonably about the future, about that which is to come. That capacity, which he denominates 'prognosis', is a part of history as a discipline, since it is history's job to study why some of these prognoses have come true and others have not. In order to do this, he appeals to his theory of the strata of time, since it enables him to determine what possibility a prognosis has of being fulfilled. The more levels a prediction encompasses vertically, the higher its probability of being accurate. He identifies different types of prognosis, according to the range of future alternatives they offer to the historical agents. There are those that he describes as 'wishful prognoses', which is to say those that are the product of the optimism (or pessimism) of an agent, without taking the pertinent factors adequately into account; then, there are those that he characterizes as 'compulsory prognoses', which present only one possible course of action and exclude any alternative; and, finally, come the 'alternative conditional prognoses' that contain instructions for a course of action for the purpose of avoiding certain results (such as the repetition of a war).

Desire-which is to say the expectation that events pan out in the way that the agent wants-is an important component of each of these, but what differentiate the three prognoses are the relationships that they have with previous historical experiences. The third type of prognosis is the one that seems to make the best use of historical experiences, insofar as it is able to present a future state of affairs that should be avoided, such as the (possible but not inevitable) repetition of a past that it would be desirable to overcome. When certain past events have been damaging to a social group, this type of prognosis attempts to extrapolate them to the future by presenting them as an outcome that can be avoided if the correct courses of action are taken (Koselleck 2002b). This observation is accurate and Koselleck expressed it in other terms in reference to the way in which social groups interpret their experiences and rewrite their history once they have been defeated. As he states in "Transformation of Experience and Methodological Change: A Historical-Anthropological Essay”: "the experience of being vanquished contains an epistemological potential that transcends its cause, espe- 
cially when the vanquished are required to rewrite general history in conjunction with their own” (2002a, p. 77).

As I pointed out earlier, the factor that Koselleck stresses, in order to gauge the precision of the prognoses, is the temporal strata that they encompass. Here, he is referring to the different structures, processes and factors that constitute historical reality, which have varying rates of change and don't respond to human action in a uniform manner. While long term factors don't directly or immediately depend upon human action, there are other short or medium term actions that can indeed be affected by it, which is why historical agents can include their modifications, to a certain degree, in the prediction of the outcomes of their actions.

I'm not going to focus on the characteristics of each of the different strata that Koselleck identifies, because what interests me here is something else. What is important is their relationship to human actions, because this is what leads to historical contingence, which is a central factor in conceiving the future in non-prophetic terms. All historical events are more or less new, which is to say more or less unpredictable, but what is important for historical comprehension is to grasp the contingent nature of their relationship to the events that came before them. It is in relation to historical contingency that the gap between prediction (the imaginable future) and its actual fulfillment can best be approached. Historical contingence enables us to conserve intact the two characteristics of future as historical time: its open condition and the degree of uncertainty that necessarily comes with it (inseparable from its availability); and, on the other hand, the fact that it is restricted to a set of options that are in a certain sense pre-determined, since that which occurs is always the product of a set of conditions, imprecise and complex, that preceded it.

As I said earlier, Koselleck is interested in how the future can be an object of study for historians, as 'future past', but some observations can be found in his analysis that in general allow us to think of the future in terms of historical time. Human beings think about the past extrapolating their experiences, but not all historical experiences are equally valuable in predicting the future. There are some, Koselleck says, that possess 'prognostic power' (2002b, p. 148)' which he calls 'meta-historical' (even if they aren't timeless). These seem to be general references to the characteristics of human action and, although they are derived from experience, they have a supra-historical value. He includes in this group what could be described as 'popular knowledge', or 'folk wisdom', often expressed through proverbs. But, these types of extrapolation from past situations to future ones possess a high level of vagueness. A prognosis with a greater possibility of turning out to be accurate will be that which includes the highest number of strata of time, which is to say that which includes a vertical temporal grad- 
uation and therefore possesses a higher number of precise references to the contexts in which the action had taken place.

This analysis should be put alongside Koselleck's thesis that in history there are processes and structures that repeat themselves, which enables him to postulate 'the formal repeatability of history'. Once again, this permits us to see to what degree the future presupposes a conjunction between novelty and repetition. The human capacity for predicting the future through prognosis requires an accurate assessment of how both factors (the new and the repeated) interact and, in addition, the capacity of the agent involved to bring about the conditions necessary for the predicted future to come to pass. It is inevitable at this point to bring Kant back into the discussion, since for him the possibility of a prophetic history necessarily implied that the person who made the prophecy was also involved in the conditions of making it come true (which doesn't seem so far-fetched if we think of the world of finance and international politics).

I'm interested in the relationship between the new and the repeated because it enables us to analyze to what degree the thought future is a dimension that is relevant for understanding how human agents and societies, in developing means to achieve what they desire, interpret available historical experiences. In the end, Koselleck concludes that in our current conditions, the variety of factors that influence our actions (as well as an increase in the rate at which those factors change) makes it difficult to formulate prognoses (2002b, p. 148). There is an interesting asymmetry here. As a historian, Koselleck is capable of accounting for future past, which is to say the way past actors were able to predict with greater or lesser precision and greater or lesser success that which would happen. As a historical actor, however, Koselleck finds himself in complete uncertainty. This asymmetry expresses, once again, the dual value of the future: as prediction and as risk.

One of the ways to evaluate the role of the future in human groups is to analyze their ways of conserving the past. In fact, the conservation of the past is necessarily related to its transmission, which is why every strategy for conserving the past takes the future into consideration. This, once again, implies a dual valuation: in first place, as risk-what is yet to come is unknown and can therefore threaten that which we treasure; and secondly, as hope-that which is to come in the future will permit us to keep the past alive. In what follows, I will continue to analyze the past in relation to these two sides of the future: as that which enables us to conserve the past, but at the same time represents the threat of losing it. 


\section{Future and memory: the past as inheritance}

The relationship between future and memory becomes clear if collective memory is conceived of as an attempt to transmit that which has been valued as a memory to new (which is to say future) generations. The origin of this line of analysis can be traced back to M. Halbwachs's studies of the 'social frameworks' of memory. The transmission of collective memory, determined by the different groups to which the individuals belong, implies an operation of bequeathing, in the sense of leaving something so that another may have access to it in the future. In this way, memory, the trace in the present of an absence and that which is 'from the past' (to use the terminology of Ricoeur 2000), contains within its structure an intention that is oriented towards the future. This is where the principal challenge of memory resides: in transmitting an experience to those who haven't had it (Vezzetti 2002, p.19). Collective memory implies a set of practices that are related to the consolidation of cultural identities that strengthen the tie between individual and community. This tie places the tension between the pretension of truthfulness (which distinguishes it from mere imagination) and loyalty to the group (without which there would be no collective memory) at the very center of collective memory. It is a practice that is consolidated through storytelling and communally shared meanings that have already been established by the time new subjects are born. ${ }^{1}$

Following this line of argumentation, the connection between the concepts of memory and inheritance starts to become visible. Inheritance, as a social mode of transferring material and cultural assets, is in itself a historiographical object of study. (Here, I dismiss inheritance in the biological sense, to the extent that what is transmitted is done so without our consent or even being aware of it, a point I will elaborate on later.) The ways in which the transferences are executed and what it is that is being transferred force us to consider the social and cultural context in which they were produced. This is why, for example, if we understand inheritance to be the practice of land transferal, Thompson points out the risk of assuming that we are dealing with a 'historical constant', when in reality what is being inherited is not only property (land in this case) but also a web of social relationships (Thompson 2000, p. 45). Cultural anthropology studies in-

1 “'Being part of' requires a narrative in which we locate ourselves and are located in. These narratives, which are seldom of our own making, are constituted through representations and performance, conveying not only who we are but also who we will come to be." (Somers 1994), quoted from: (Anico \& Peralta 2009, p. 1) 
heritance as the transmission of objects (relics and remains) and of meanings (traditions). ${ }^{2}$

In addition to these historiographical and anthropological resonances, inheritance can be conceived of as Koselleck's experiential space, that is, as a cultural reserve that one generation attempts to transfer to another. Even when experiences crystallize into a 'space', the availability of that space is not synonymous with its actual use. In a similar fashion, inheritance contains within it uncertainty regarding its own future. One generation may leave a memorial legacy, but is faced with the uncertainty of not knowing whether or not the next generation will accept it. As Hassoun indicates, the 'adventure' of the transmission of an inheritance is the product of the difference between our ancestors and ourselves, a dynamic that will then be repeated between us and our descendants, which means that there is never 'an eternal return' of the legacy to be transmitted and that a considerable part of it is composed of oversights and annexes (Hassoun 1996). In complex societies like our own, in which traditions come into conflict and it becomes impossible to integrate past events into a singular social narrative, inheritance is a symbolic and cultural space where identities in contention within the common space are put into question. ${ }^{3}$ More than a fixed and closed repertoire of shared meanings, inheritance should be thought of in this manner-as an attempt to solidify identities and meanings that are unstable and fragmentary (Betts \& Rose 2015, p. 2). The construction of collective memory, as with all forms of social inheritance, is also riddled with conflicts and threatened by a proliferation of contents and formats that con-

2 In the introduction of the issue of the publication "Past and Present” with monographs about relics and remains, it is stated that the essays presented in the issue "explore the political, economic and social dimensions of the identification, preservation and fabrication of relics and remains, and their meaning and function in the spheres of memory, history and heritage" (Walsham 2010, p. 10, italics added). The supplement corresponding to July of 2015 of the same publication is dedicated to inheritance in the modern world and, while it focuses on the study of historical preservation, its origins and re-significations throughout time, a quick look at the table of contents is enough to see the close relationship that exists between inheritance and collective memory (Betts \& Rose 2015).

3 In the case of Argentina, think of the debates concerning the monuments to Julio A. Roca, the general who headed the 'desert campaign'-which in reality consisted of the extermination of the indigenous populations that had inhabited Patagonia during the nineteenth century. Today, there are many efforts to remove the monuments that commemorate Roca in different cities throughout the country, a movement that cancels the idea that our country was established peacefully upon an enormous, uninhabited territory-an idea created and strengthened by traditional historiography. 
tribute to its consecration or banalization (Todorov 2002-in particular, chapter 3).

\section{(Preliminary) conclusions}

The concept of 'inheritance' contains various meanings, but it essentially implies something that people take with themselves and which comes from others before them, their ancestors. The construction of an inheritance implies the hope that the temporal and generational gap can be bridged and that it is possible to be able to use today that which has been passed on to us. ${ }^{4}$

Inheritance also refers to that which human beings carry within themselves without being conscious of it. Oakeshott, for example, refers to genetic inheritance, the information coded in our DNA, which has accumulated throughout centuries of evolution and which we haven't done anything to receive nor made an effort to preserve. It's just there, available to us without our even knowing (Oakeshott 1999). This notion of biological inheritance does not apply to history. Another form of inheritance would have to be postulated, understood in, say, 'biographical' terms. I'm referring to an inheritance which includes an enormous number of conducts, valuations, meaning constructs, etc. that people acquire throughout a long learning process that begins at birth and continues all throughout life.

There is a third form of inheritance, which is the one that I would like to analyze here and which has to do with everything that subjects receive through their social and community context. Understood in this way, inheritance is properly historical, and it is composed of a great variety of what we can call 'goods', which historical agents are able to apprehend more or less consciously and whose meanings are more or less explicit to them. The historical inheritance that I'm referring to here implies capital that is composed of dissimilar goods being passed from one generation to another. It is important to stress that social actors can be beneficiaries of more than one inheritance, as long as there are, in our society, different groups to belong to, with varying degrees of intimacy or distance (Halbwachs classifies 'belonging groups' as the near, the dear and the far). This historical inheritance, which is close to different manifestations of collective memory, operates with varying degrees of opaqueness. In the same way as genetic inheritance, this historical memory is also handed down to new generations without their consent but, in contrast to genetic inheritance, it requires some

4 I owe some of these ideas about inheritance to Prof. Estanislao Antelo. 
level of acceptance on behalf of the recipients in order to be put into action. It is an offer available to new subjects that would then have to be activated by them.

In all historical inheritance, there are those who bequeath and those who receive the legacy. This inheritance demands a particular attitude from both parties to ensure that its reception takes place. There are cases of legacies lovingly prepared by one generation for the next that nonetheless sink into oblivion. But there are also cases in which the successors lay claim to a legacy that their ancestors did not make available to them. There could be many reasons why these kinds of cases might happen, from the fact that the inheritance is rendered useless or embarrassing in its new context to the fact that the present raises new questions concerning the past from which the inheritance comes. The questions we have to ask ourselves, then, are about how shared inheritances are constituted, how they are composed and how available they are to those who intend to use them.

As I already mentioned while discussing A. Danto's thesis concerning historians (we can't know what history will be written in the future because we don't know which interests will guide coming historians nor which questions they will address), we can also approach historical inheritance in this same way. Societies can more or less consciously use symbolic constructs, examples, moral tales, lineages, etc. to compose the heritage that they wish to transmit to coming generations. They cannot predict, however, the course that these inheritances will take in the future; it isn't possible to predict in detail how future generations will use them, if they even use them at all. It is in historical inheritance that the way in which communities attempt to deal with the future in its dual aspect, as risk as well as prediction, can be observed. In the first case, the future may bring the loss of value, a fall into disuse or the distortion of an inheritance. In the second case, the future becomes a necessary condition for the possibility of the transmission of that which is being preserved. The words that R. Kent, an Auschwitz survivor, spoke in January of 2015 are worth remembering here: "we do not want our past to be our children's future". He is referring to an inheritance, that of hardships suffered, trying to be preserved for the future (in order to prevent it from being repeated) but that, in addition, acknowledges the open character of the future, since that which is to come may or may not do justice to that inheritance. ${ }^{5}$

5 In the manner of Koselleck's aforementioned 'alternative conditional prognosis'. R. Kent's speech was given on $25^{\text {th }}$ January, 2015 and is available at: http://www.auschwitz.info/en/es sentials/essential-speeches/2015-roman-kent.html, date of register: 09/09/15 
While it's true that the historical inheritance presented here bears resemblance to collective memory, it is important to point out some of the differences. The latter, generally speaking, is the product of the effort of a community, or even a state, to constitute shared symbolic assets and through which several more or less successful mechanics of transmission can be identified (especially through, but not limited to, the educational system). As such, the features of what I am calling historical inheritance aren't as defined and its modes of transmission aren't as lineal. Its constitution and regulation consolidate the generational and intergenerational bond, and the possibility of its transmission implies challenging the ever-present risk of being forgotten. Historical inheritances are formally instituted in order to be handed down through established mechanisms of construction and, even more importantly, of transmission and conservation. At the same time, though, they can be re-created (re-signified) with each new generation, who will take from this inheritance what they deem useful.

It seems to me that the idea of historical inheritance that I am presenting here sets a limit to the uses of the concept of collective memory. Actually, the latter always runs the risk of being substantialized, of losing sight of its polemic and plural character, and at the same time it has a complex relationship with official memory. Historical inheritance, on the other hand, displays several characteristics that I think would be revealing to explore:

1. it is shared by social groups of varying size, within which the intensity of the bonds that hold them together range from subtle to close, in the same way that the bond can either be explicitly sustained or not;

2. it has a potential value that can either be activated or not according to the contexts within which it is advocated; and

3. it possesses an open meaning whose future re-significations are impossible to determine a priori.

In other words, inheritance is defined not only by its relationship to the past that it seeks to preserve and transmit, but also by its orientation towards the future, since this is what characterizes every inheritance, that is to say its future availability. What defines inheritance is the fact that it is made available to others, those of the future, with whom those who compiled it intend to share it. Yet, at the same time that it offers the possibility of historical comprehension, like a bridge between two temporal (generational) moments, it also exposes its limits. The open condition expressed in the meaning of inheritance prevents us from being certain that it will be used towards the same end for which it was intended. What's more, it prevents us from being certain that it will even be useful at all in the future. In this manner, the construction of a historical inheritance that intends to be shared implies the instituting gesture of the giver while it, inevitably, 
leaves the decision regarding its use and pertinence in the hands of the receiver. The construction of an inheritance in itself presupposes and at the same time problematizes the temporal continuity expressed through generational continuity.

But there is another characteristic that I wish to point out. Historical inheritance, in contrast to other, 'legal' inheritances, cannot avoid being appropriated by those who feign (or truly believe), to be its heirs, without being the originally intended recipients. Historical inheritance contains an aporia: it is the result of the conscious and deliberate effort of previous generations to pass on to others a body of specific symbol capital without being able to guarantee who its actual heirs will be. Even further, they cannot even guarantee that the inheritance handed down will be transmitted in the way it had been intended, given that younger generations are capable of constructing new, contingently defined ties to the past-ties, in other words, that are neither authorized by nor contained in the original meaning intended to be associated with that inheritance. This idea of the past as inheritance enables us to characterize the relationship that social communities establish with their past, while simultaneously helping us to avoid thinking of the past only in terms of its ontological or referential persistence (which I don't dispute).

As a result, I would like to conclude by claiming that the past exists in the form of an inheritance that is reclaimed by those who were not its contemporaries. Since this reclamation cannot be controlled a priori, it is impossible to define the past a priori, independent of the meanings by which it becomes operative. Rather than an object in an attic or a territory to be explored, the past emerges as symbolic capital to be inherited (accepting or disputing its meaning). In other words, the past will be that which the future allows it to be.

\section{Bibliography}

Anico, M., \& Peralta, E. (2009): Heritage and identity: engagement and demission in the contemporary world. London, New York: Routledge / Taylor \& Francis Group.

Arendt, H. (1968): “The Crisis in Education”. In: Between Past and Future. New York: Penguin Books.

Betts, P. / Ross, C. (2015): Heritage in the modern world: historical preservation in global perspective, Past and Present, 226 (suppl 10). Oxford: Oxford University Press

Danto, A. (1985): “Analytical philosophy of history”. In: Narration and Knowledge. Columbia University Press.

Hassoun, J. (1996): Los contrabandistas de la memoria. Buenos Aires: Ediciones de la Flor. 
Koselleck, R. (2002a): "Transformations of Experience and Methodological Change: A Historical-Anthropological Essay”. In: The practice of conceptual history : timing history, spacing concepts. California: Stanford University Press.

Koselleck, R. (2002b): “The Unknown Future and the Art of Prognosis”. In: The practice of conceptual history : timing history, spacing concepts. California: Stanford University Press.

Oakeshott, M (1999): “Present, Past and Future”. In: On History and Other Essays. Indianapolis: Liberty Fund.

Ricœur, P. (2000): La mémoire, l'histoire, l'oubli. Paris: Le Seuil.

Thompson, E. P. (2000): Agenda para una historia radical. (Grau, E.-translation into Spanish). Barcelona: Crítica.

Todorov, T. (2002): Memoria del mal, tentación del bien: indagación sobre el siglo XX. (Serrat Crespo, M.-translation into Spanish). Barcelona: Península.

Vezzetti, H. (2002): Pasado y presente: guerra, dictadura y sociedad en la Argentina. Buenos Aires: Siglo XXI.

Walsham, A. (2010): “Introduction: Relics and Remains”. In: Past \& Present, 206 (suppl 5), pp. $9-36$. 
